\title{
IMAGEM DO ESTETICISTA SOB A ÓTICA DOS STAKEHOLDERS
}

\section{THE IMAGE OF THE BEAUTICIAN FROM THE PERSPECTIVE OF THE STAKEHOLDERS}

\author{
Izabela Teixeira Dias \\ Mestre em Administração pelo Centro Universitário UNA \\ Belo Horizonte, MG, Brasil \\ Email: belatdias@hotmail.com \\ Fernanda Carla Wasner Vasconcelos \\ Professora do Mestrado Profissional em Administração do Centro Universitário UNA \\ Belo Horizonte, MG, Brasil \\ Email: fernanda.wasner@prof.una.br \\ Gustavo Quiroga Souki \\ Professor do Mestrado Profissional em Administração do Centro Universitário UNA \\ Belo Horizonte, MG, Brasil \\ Email: gustavo@souki.net.br
}

\section{RESUMO}

Este trabalho averiguou a percepção dos stakeholders sobre a imagem da profissão e do profissional da Estética. Para tanto, foi realizada uma pesquisa qualitativa e descritiva, por meio de 49 entrevistas semiestruturadas. Os entrevistados foram solicitados a fazer desenhos sobre a profissão e do profissional da Estética, ilustrando os depoimentos obtidos. Os depoimentos foram analisados utilizando a base teórica sobre as dimensões da imagem De Toni, Milan e Schuler. Os resultados mostram: (i) dimensão cognitiva - a responsabilidade em relação à beleza e à saúde são inerentes às atividades profissionais; (ii) dimensão funcional - cuidados com pele, unhas, aspectos relacionados à aparência e a necessidade de constante aprimoramento profissional; (iii) dimensão simbólica mostrou que profissionais de Estética melhoram a autoestima, promovem bem-estar e geram satisfação aos cientes; (iv) dimensão emocional, foram citados relatos de emoções positivas em relação à prestação de serviços e aos resultados atingidos. Este trabalho inova ao utilizar conceitos de imagem e de marketing para analisar a profissão e o profissional da Estética, trazendo contribuições gerenciais e acadêmicas.

Palavras-chave: Estética. Esteticista. Imagem profissional. Stakeholders.

\section{ABSTRACT}

This paper investigated the perception of the stakeholders about the image of the beauticians and their profession. For that, a qualitative and descriptive research was carried out, through 49 semi-structured interviews. The interviewees were asked to make drawings about the profession and the professional of Aesthetics, illustrating the testimonials obtained. The statements were analyzed using the theoretical basis on the image dimensions by De Toni, Milan and Schuler. The results show: (i) cognitive dimension responsibility for beauty and health is inherent to professional activities; (ii) functional dimension - skin care, nails, aspects related to appearance and the need for constant professional improvement; (iii) symbolic dimension showed that beauticians improve self-esteem, promote well-being and generate satisfaction for the clients; (iv) emotional dimension, there were reports of positive emotions in relation to the provision of services and the results achieved. This work innovates when using concepts of image and marketing to analyze the beauticians and their profession, bringing managerial and academic contributions.

Keywords: Aesthetics. Beautician. Professional image. Stakeholders. 


\section{INTRODUÇÃO}

As imagens possuem um papel fundamental no direcionamento estratégico das organizações, pois permitem moldar o pensamento e direcionar as ações estratégicas das organizações (MACHADO-DA-SILVA; FONSECA; FERNANDES, 2000; GONZALEZ; CHAKRABORTY, 2012).

$\mathrm{Na}$ construção da imagem de profissões, pessoas, marcas (e também de empresas), é importante lembrar que há uma interrelação entre as suas dimensões cognitiva, emocional, funcional e simbólica (DE TONI, 2005; DE TONI; SCHULER, 2007).

A imagem profissional pode ser definida como um conjunto de percepções de pessoas chave (clientes, chefes, subordinados e colegas) sobre a competência e caráter do profissional no ambiente de trabalho (IBARRA, 1999; TICE; WALLACE, 2003; LITTLE et al., 2015). A imagem profissional desempenha um papel crítico na vida organizacional em virtude de suas implicações para a aprovação social, poder, bemestar e carreira de sucesso (BAUMEISTER, 1982; IBARRA, 1999; LEARY; KOWALSKI, 1990; ROSENFELD; GIACOLONE; RIORDAN, 2001; SCHLENKER, 2003; HOEVE; JANSEN; ROODBOL, 2014; LITTLE et al., 2015). Por consequência, as pessoas que constroem imagens profissionais aceitas são percebidas como capazes de atender às exigências técnicas e sociais de suas atividades laborais (GIACALONE; ROSENFELD, 1991; IBARRA, 1999).

Compreender a imagem profissional que diversos públicos têm sobre determinada profissão, e sobre os profissionais da área, constitui uma vantagem competitiva no que se refere ao direcionamento de estratégias, bem como uma ferramenta de comunicação efetiva que favorece um bom posicionamento desse profissional no mercado. Sendo assim, acredita-se que a compreensão da imagem profissional possa contribuir para a formulação e implementação das estratégias de marketing, importantes para direcionar ações estratégicas.

A Estética é uma profissão supostamente antiga, mas sua relevância é pouco estudada e comprovada. Porém, é possível verificar que o crescimento do setor de serviços na área da Estética tem aumentado significativamente. Tal comportamento se reflete na economia, seja no crescimento da indústria de perfumaria e cosméticos, seja na prestação de serviços (procedimentos estéticos) (SEBRAE, 2015).

Acredita-se que a inexistência de um órgão regulador de leis e/ou regras para essa profissão tem contribuído para a formação de uma imagem profissional distorcida. Assim, os Esteticistas deveriam rever seus paradigmas de atuação, recorrendo as premissas do marketing para obter sucesso profissional.

Desta forma, a compreensão da imagem que os diversos stakeholders possuem dessa profissão e desse profissional poderá fornecer subsídios para a criação de estratégias que permitirão melhorar a qualidade dos serviços prestados, ampliar a linha de produtos/serviços oferecidos, posicionar adequadamente esses profissionais perante seus stakeholders, buscar maior valorização profissional e construir uma imagem mais nítida perante os clientes (MENDES; SOUKI; GRASSELI, 2008).

Por este motivo, o presente estudo teve como objetivo averiguar a percepção dos stakeholders da Estética em relação à imagem da profissão e do profissional em suas dimensões cognitiva, funcional, simbólica e emocional. 


\section{IMAGEM E SUAS DIMENSÕES}

Imagens constituem instrumentos utilizados pelo homem, sendo o elemento cognitivo básico do pensamento capaz de influenciar e direcionar o pensamento (DE TONI; SCHULER, 2007; MILAN; DE TONI, 2008). A partir das imagens, é possível determinar quais informações receberão mais atenção ou não, e como as pessoas expressam o modo como veem ou representam um objeto (RODRíGUEZ et al., 2014).

Para o marketing, a imagem possibilita compreender o comportamento do consumidor, identificando suas conviç̧ões, atitudes e impressões sobre um objeto (produto, marca, corporação, serviço e loja) (BARICH; KOTLER, 1991; STERN; ZINKHAN; JAJU, 2001).

Desta forma, a imagem é a impressão que permanece na mente das pessoas. Essa impressão se aplica (ou se refere) a diversas áreas, tais como: impressão da profissão (como as pessoas veem e valorizam ou desvalorizam determinadas profissões), imagem da empresa (a maneira como as pessoas veem a corporação como um todo), imagem de uma marca (a forma como as pessoas afrontam uma marca em particular que está em concorrência com outras marcas), de um produto (como as pessoas percebem uma categoria de produto em particular) (DICHTER, 1985; BARICH; KOTLER, 1991; JOLY, 2003; ZIELKE, 2011).

Com base nos entendimentos de Dobni e Zinkhan (1990), De Toni (2005), Milan, Gasparini e De Toni (2013) e Milan et al. (2014) foram identificadas quatro dimensões (cognitiva, funcional, emocional e simbólica) para os estudos sobre a imagem de serviços e produtos.

Segundo o estudo realizado por Milan e colaboradores (2014), foi possível verificar que a imagem de um produto ou serviço apresenta um conceito multidimensional, formada pelas dimensões funcional, cognitiva, emocional e simbólica, que geram impacto na percepção de valor, influenciando na decisão de compra do consumidor. Várias pesquisas têm utilizado essas dimensões para a avaliação da imagem de serviços, a saber: fisioterápicos (DE TONI; MILAN; BARAZETTI, 2004; AMORIM, 2007), arquitetônicos (GRASSELI, 2007), de telefonia celular (DE TONI; SCHULER, 2007), psicológicos (MENDES, 2008; LOPUKHOVA, 2014), do intercâmbio de cursos de idioma (VICTER, 2009), de programas de orientação e proteção ao consumidor (MACHADO, 2010), fonoaudiológicos (ALMEIDA, 2011), de um shopping center (GASPARIN, 2011), de acessórios de esquadria de PVC (MILAN et al., 2014) e farmacêuticos (FERREIRA, 2014; FERREIRA; MOURA; SOUKI, 2014).

A dimensão cognitiva refere-se às construções mentais, racionais e lógicas que o indivíduo desenvolve sobre o produto ou serviço. A imagem formada a partir dessas construções pode ser influenciada pelas crenças e conhecimento prévio que o indivíduo tem em relação ao produto ou serviço. Dessa forma, o indivíduo avalia a imagem como um conjunto de impressões, percepções e atitudes relativas ao prestador de serviço, considerando aspectos relativos à pessoa, ao contato direto, à transação e à relação custo/benefício, além das instalações da empresa (DOBNI; ZINKHAN, 1990; LOVELOCK; WRIGHT, 2005; DE TONI; SCHULER, 2007; MILAN; GASPARINI; DE TONI, 2013; MILAN et al., 2014).

A dimensão funcional refere-se às características percebidas por usuários durante o processo de prestação de serviços: instalações físicas do ambiente, equipamentos, aparência das pessoas, material impresso e outras indicações visíveis, expressando a qualidade por meio de elementos tangíveis (DE TONI; MILAN; SCHULER, 2005; LOVELOCK; WRIGHT, 2005). 
No que tange à dimensão emocional, há um conjunto positivo ou negativo de sentimentos, emoções e estados de ânimo que o indivíduo possui em relação a determinado produto ou serviço. Envolve as experiências internas que o motiva a organizar as imagens e a guiá-las em suas ações (LEDOUX, 2001; O'NEILL; LAMBERT, 2001; DE TONI; SCHULER, 2007; MILAN; GASPARIN; DE TONI, 2013; MILAN et al., 2014).

A dimensão simbólica implica que serviços ou produtos são avaliados pelo que significam ou representam para o indivíduo. Assim, o valor simbólico ou a imagem é a extensão que realça o valor da pessoa aos seus próprios olhos (autoestima) e aos olhos dos outros (status). Essa dimensão lida com o objeto de forma abstrata, pois o que as pessoas adquirem tem um significado pessoal, hedônico e social, além de suas funções utilitárias (DOBNI; ZINKHAN, 1990; MILAN; DE TONI; SCHULER, 2010; MILAN; GASPARINI; DE TONI, 2013).

\section{METODOLOGIA}

Para alcançar o objetivo proposto, realizou-se uma pesquisa de campo, de natureza qualitativa, na qual foram feitas 49 entrevistas em profundidade com diversos stakeholders envolvidos com a Estética, a saber: 4 esteticistas atuantes, 4 esteticistas não atuantes, 4 professores (sendo 2 técnicos e 2 graduadas por categoria); 2 alunos de graduação; 2 alunos de curso técnico em Estética e 2 coordenadores de curso; 1 representante do sindicato, 4 clientes atuais, 4 clientes que interromperam a prestação de serviço, 4 clientes que concluíram a prestação de serviço, 4 clientes em potencial para os serviços de Estética e outros profissionais das áreas de sombreamento com a Estética - médico dermatologista (2) e de medicina estética (2); fisioterapeuta dermatofuncional (2); biomédico esteta (2) e profissionais que tem seu ofício ligados à Estética (6).

Os stakeholders foram selecionados por conveniência e acessibilidade, as entrevistas foram feitas com gravação em áudio, transcritas fidedigna e integralmente e os dados obtidos tiveram seu conteúdo analisados conforme Bardin (2011).

Foram utilizados roteiros de entrevistas, de caráter semiestruturado, criados para cada categoria de stakeholders, descritos na Figura 1, nos quais também foi solicitado que os participantes se manifestassem desenhando figuras que representassem os profissionais de Estética. Para este estudo, a adoção da construção do desenho não-estruturado se configurou em um recurso ilustrativo das palavras-chaves e frasesresposta a ele associadas. Tais desenhos se transformaram em um elemento auxiliar na análise das entrevistas. 
Figura 1 - Modelo de avaliação da imagem do Esteticista.

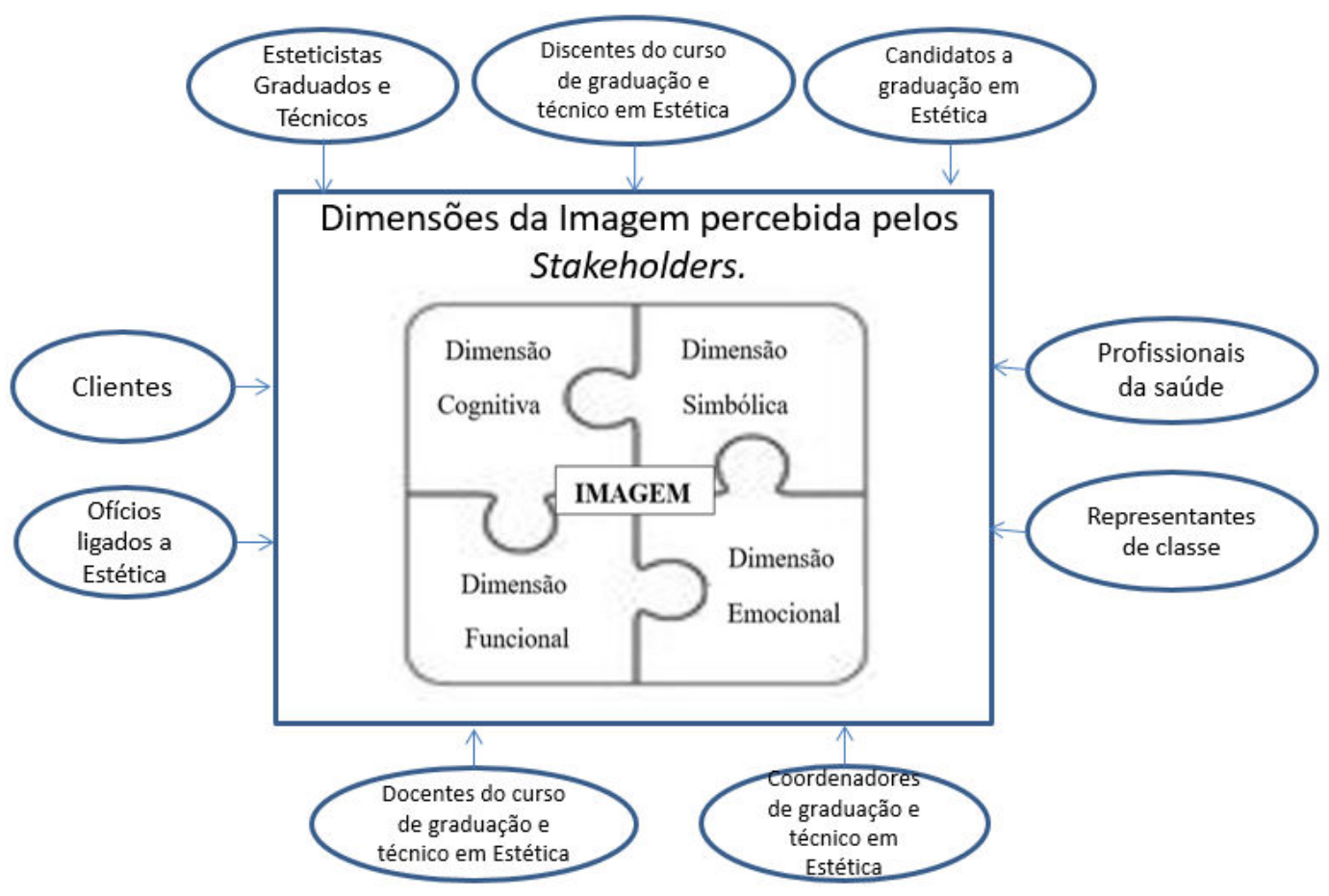

Fonte: Dados da pesquisa.

\section{RESULTADOS E DISCUSSÃO}

Para contribuir com o entendimento dessa análise, identificou-se a imagem da profissão e do profissional de Estética conforme seus stakeholders. Para este fim, utilizou-se a perspectiva das dimensões propostas por De Toni (2005), De Toni, Milan e Schuler (2005) e De Toni e Schuler (2007).

\section{Dimensão Cognitiva}

Buscou-se verificar qual o conhecimento que os diversos stakeholders têm das tarefas desempenhadas pelos esteticistas e da maneira como esses stakeholders se posicionam em relação à profissão e ao curso de Estética. Na maior parte das declarações, constatou-se que a profissão está ligada apenas aos tratamentos estéticos, como descrito a seguir:

"Tratamentos como limpeza de pele, depilação a laser, peelings faciais, tratamento estético de estrias, tratamento de pré e pós-operatórios, massagem relaxante, aromaterapia, drenagem linfática, tratamento de gordura localizada, de celulite, acho que é isso". (Depoimento de Esteticista atuante).

"Trabalha com estética facial, tratamento de acne, rugas, manchas. E tem também a estética corporal pra tratamento de estrias, celulites, gordura localizada, massagens relaxantes". (Depoimento de Esteticista não atuante).

"Massagens, limpeza de pele e alguns tipos de peeling, ah, e também drenagem". (Depoimento de Biomédico). 
Esses depoimentos podem ser ilustrados pela Figura 2, na qual as atividades da profissão foram representadas por diversas áreas nas quais o profissional pode atuar, além da necessidade de estudar sempre.

Figura 2 - Dimensão Cognitiva da imagem: atuação do esteticista por uma estudante de graduação.

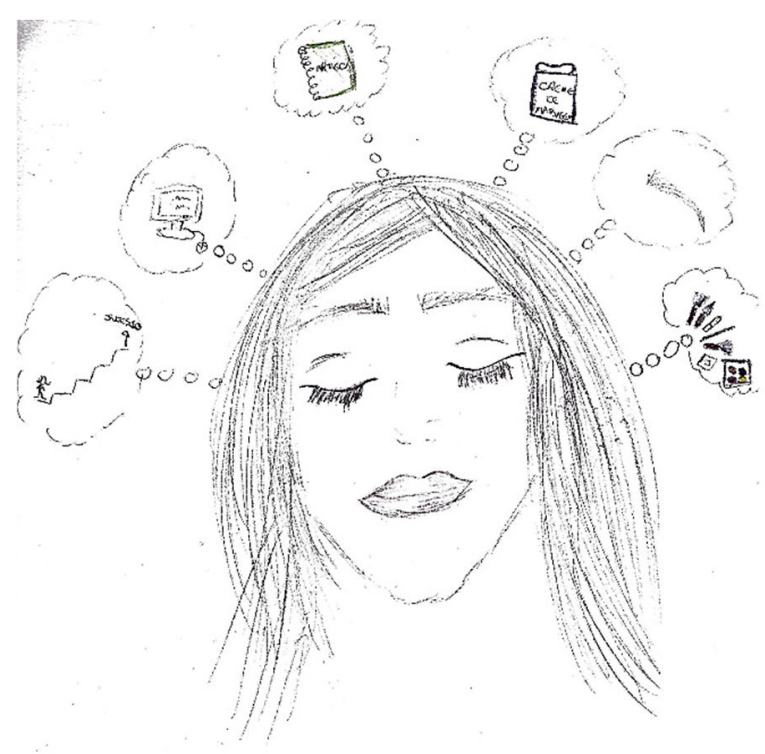

Fonte: Dados da pesquisa.

Para alguns stakeholders, a profissão de Estética não está relacionada apenas à beleza, mas também à saúde. Os depoimentos a seguir evidenciam a importância da Estética ser incluída na área da saúde.

"Eu não enxergo a estética como beleza, eu enxergo como saúde (...) Eu acho que a estética tem que ser ver mais como um campo de saúde do que como um campo de beleza. Porque ela tem um potencial de saúde imenso e ela não tá sabendo usar isso". (Depoimento de professor de curso de Estética).

"A estética está migrando suas atividades que antigamente era voltada somente para o embelezamento, e hoje é saúde, é o bem-estar das pessoas. Hoje, a profissão, ela exige mais conhecimento anatômico e fisiológico pra conseguir ter um atendimento especializado, cada ser humano tem a sua necessidade. Hoje temos mais conhecimento nessa profissão". (Depoimento de coordenador de curso de Estética).

A Figura 3 ilustra a atuação do profissional da Estética na área da saúde. O coração junto com o símbolo da saúde, representam as afirmativas citadas nos depoimentos. 
Figura 3 - Dimensão cognitiva da imagem: Estética na área da saúde, por coordenadora de curso técnico em Estética.

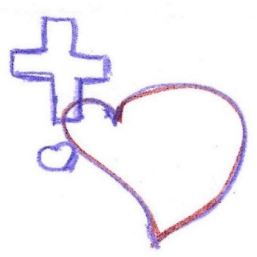

Fonte: Dados da pesquisa.

Na percepção dos esteticistas formados e dos estudantes de Estética, o curso seria mais fácil por se tratar apenas de beleza, mas com a vivência, viram que o curso aborda não só beleza, mas, principalmente, saúde além de trabalhar o emocional das pessoas.

"Sim, porque antes quando se falava em estética, pensava-se só na facial. Hoje o conceito é mais amplo e o curso nos prepara para tal". (Depoimento de estudante de Estética).

"Pensava na Estética como meio de embelezamento, só que depois do curso eu vi que a beleza seria mais uma ferramenta que é gerada pelo conhecimento". (Depoimento de Esteticista atuante).

"Via como uma profissão de cuidados com corpo e o bem-estar físico, com o objetivo de buscar o belo nas pessoas. Depois que fiz o curso, percebi que é algo mais profundo que tem a ver com a saúde física e mental das pessoas". (Depoimento de Esteticista não atuante).

Nas declarações a seguir, a imagem do Esteticista está delineada como um profissional capacitado para tratar o problema estético, além de gerar cuidado, bem-estar, relaxamento e melhorar a autoestima das pessoas. Também é considerado um profissional bom ouvinte.

"O esteticista cuida das pessoas, ele te orienta, te explica, te direciona pra um tratamento corporal ou facial, que seja para embelezar, manter a pele bonita, ressaltar ou até pra relaxar". (Depoimento de Esteticista atuante).

“... como a oportunidade de cuidar, ouvir e, muitas das vezes, somos um mais que profissional realizando um procedimento e sim uma ouvinte que irá fazer a diferença na vida dos que passam pelas mãos da esteticista". (Depoimento de Esteticista não atuante).

Assim, está representada a imagem do esteticista como alguém que é bom ouvinte, conforme a Figura 4. Nela, o profissional e o cliente/paciente estão um de frente ao outro como se estivessem num ambiente de consultório. 
Figura 4 - Dimensão cognitiva da imagem: profissional que é bom ouvinte, por médico de medicina estética.

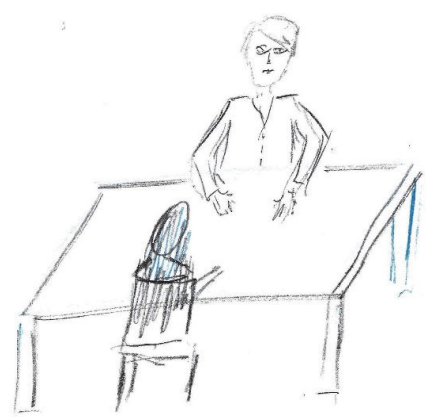

Fonte: Dados da pesquisa.

Para os clientes/pacientes, o esteticista foi o profissional escolhido por eles para tratamentos estéticos, cuja função é a de melhorar a aparência das pessoas.

"Busquei melhoria de minha aparência". (Depoimento de cliente/paciente que interrompeu tratamento estético).

"Melhoria no meu visual. Fiz um tratamento facial pra melhorar minha pele, aí acabei inventando de fazer outras coisas". (Depoimento de cliente/paciente que interrompeu tratamento estético).

"Bom, queria melhorar minha pele e a famosa celulite. Mulher sempre tem as mesmas queixas. A gente sempre quer se sentir bem". (Depoimento de cliente/paciente em tratamento estético).

O Esteticista, profissional capacitado para tratar de aspectos ligados à estética, além de gerar cuidado, bem-estar, relaxamento e melhorar a autoestima, é visto pelos stakeholders como um profissional que necessita da ajuda dos clientes para obter resultados com o tratamento:

"Colaborar e seguir à risca as orientações. Se ele não fizer a parte dele mágica não existe". (Depoimento de cliente/paciente que interrompeu tratamento estético).

"É essencial para o resultado do tratamento, ele deve cumprir o que o profissional recomenda". (Depoimento de cliente/paciente em tratamento estético).

“... se você passa um tratamento pra ele realizar em casa, se a pessoa não cuidar aí ela não vai ter muita melhora não. Ela vai vir aqui vai fazer o procedimento, vai ter uma melhora ali na hora, mas se não fizer a parte dela, o homecare que a gente fala, não vai ter evolução não". (Depoimento de Esteticista atuante).

A relação de ajuda do cliente/paciente no tratamento estético aparece ilustrada nas Figuras 5A e 5B. 
Figura 5 - Dimensão cognitiva da imagem: profissional que necessita da ajuda do cliente por (5A) ofício de cabeleireiro, (5B) coordenadora de curso técnico em Estética.

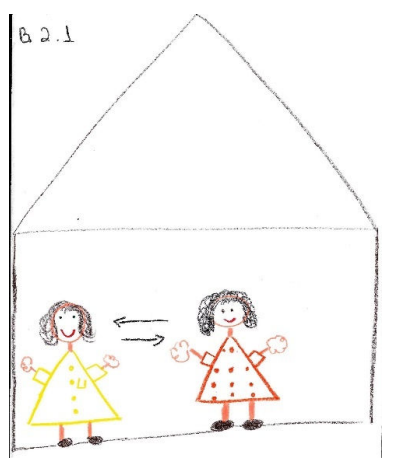

Fonte: Dados da pesquisa.

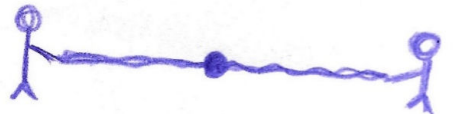

5A

5B

Para alguns entrevistados, alguns profissionais da Estética são vistos como profissionais que só visam o lucro, conforme os depoimentos.

“(...) mas como toda profissão, existem aquelas pessoas que realmente só buscam a parte financeira do negócio, onde ela não visa o bem estar do paciente e, sim, o bem estar financeiro dela mesmo. Mas isso é presente em todo profissional". (Depoimento de Biomédico).

“(...) Alguns só veem o lado financeiro da coisa, já outros querem fazer de tudo pra agradar e dar o resultado que o cliente espera. Acho que isso acontece em toda profissão, né, sempre tem os interesseiros, só querem o dinheiro. (...)". (Depoimento de professor de curso de Estética).

Percebe-se que os stakeholders da Estética compreendem o campo de atuação da profissão, mas muitos deles veem o esteticista como alguém capaz de escutar os problemas pessoais dos clientes/pacientes e aconselhá-los. Essa perspectiva extrapola as suas atribuições profissionais, já que essas questões são trabalhadas por psicólogos e terapeutas. A Estética foi regulamentada pela Lei no 13.643/2018 (BRASIL, 2018) e não foi enquadrada nem na área da beleza nem da saúde. Essa indefinição legal pode causar conflitos nas atribuições profissionais que têm interface com a área da saúde.

Outra questão levantada é o fato do esteticista ser o profissional capacitado para atuar na Estética, sendo capaz de cuidar, promover bem-estar, relaxamento, autoestima e por melhorar a aparência dos clientes/pacientes. Entretanto, alguns stakeholders relatam que alguns esteticistas podem ser vistos como profissionais que só visam o lucro, pois relatam que os tratamentos são feitos apenas quando se pode pagar por eles ou que estão sempre sendo complementados (um após o outro).

\section{Dimensão Funcional}

Foram identificadas as características tangíveis observadas pelos stakeholders em referência ao profissional esteticista e à profissão de Estética. Os diversos stakeholders entrevistados, incluindo esteticistas atuantes e esteticistas não atuantes, abordaram o fato de que os esteticistas devem usar roupas brancas que transmitem a noção de higiene e limpeza, devem ter boa aparência e ter alguns cuidados quanto ao uso dos 
equipamentos de proteção individual (EPI). Além disso, algumas características do local de trabalho, como: ambiente claro, limpo, calmo, confortável, organizado e tranquilo foram evidenciadas pelos diversos stakeholders, conforme mostram os depoimentos a seguir, em que foram enfatizadas palavras-chave comuns.

"Ambiente calmo, tranquilo, arejado e claro". (Depoimento de professor de curso de Estética).

"Tem que ser um ambiente totalmente tranquilo, clean, com cores que transmitam paz, segurança, harmonia, dentre outras coisas". (Depoimento de Esteticista atuante).

"Eu descreveria como eu tentei fazer aqui pra mim. Um ambiente limpo, calmo, silencioso, tranquilo, com uma musiquinha de fundo". (Depoimento de Médico).

Cabe destacar que, no que se refere à característica do contexto do trabalho, observou-se em repetidas vezes uma vinculação da importância da individualidade no atendimento em um ambiente com clima calmo e tranquilo, onde o cliente chega para relaxar - o que é demonstrado pelos depoimentos a seguir.

"Um ambiente tranquilo, limpo, uma relação mais assim do terapeuta com o seu paciente com cabines individuais, atendimento individual, é mais ou menos assim". (Depoimento de Fisioterapeuta).

"Um ambiente que o paciente chega pra relaxar. Um ambiente sem ter conversas paralelas, sem ter contato muito dentro, né, com outros pacientes, né? Então, um ambiente calmo, de limpeza, de confiança, credibilidade". (Depoimento de Médico).

"O ambiente tem que ser limpo e calmo, detesto falatório na minha cabeça quando estou me tratando e a aparência o mais claro possível". (Depoimento de cliente/paciente que concluiu o tratamento estético).

As Figuras $6 \mathrm{~A}$ e $6 \mathrm{~B}$ confirmam que o ambiente de trabalho do esteticista deve ser calmo e tranquilo para que o cliente possa relaxar. Na figura $6 \mathrm{~A}$, o cliente/paciente está deitado na maca e seu semblante mostra sua felicidade/satisfação, com sorriso no rosto. E, na figura $6 \mathrm{~B}$, o cliente/paciente também se encontra deitado em uma maca, dormindo, e o profissional diz a ele que pode relaxar.

Figura 6 - Dimensão funcional da imagem: ambiente de trabalho.
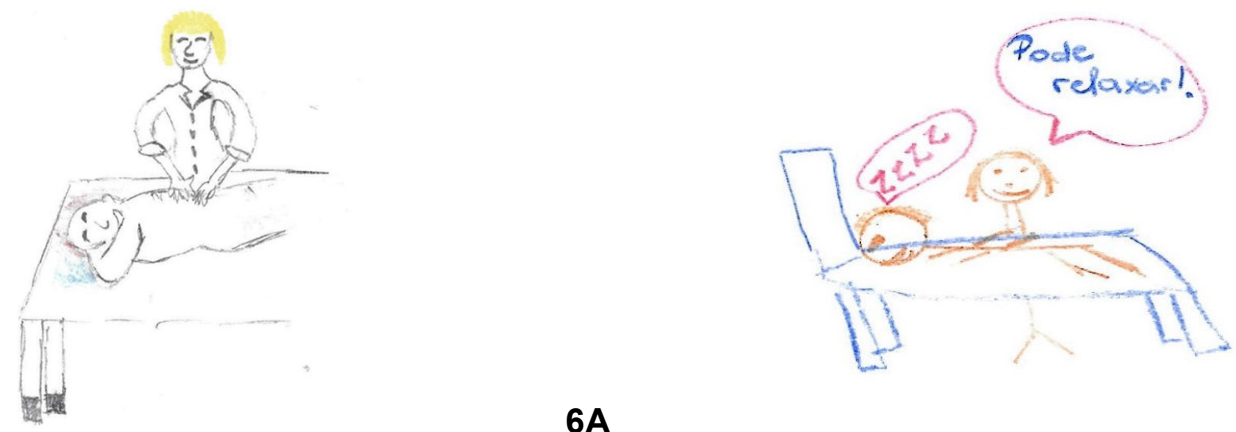

Fonte: Dados da pesquisa.

Nota: Desenhos desenvolvidos por: esteticista atuante (6A); estudante de curso de graduação em Estética (6B). 
Alguns posicionamentos quanto à dimensão funcional se relacionaram à presença de equipamentos/aparelhos no local de trabalho do esteticista. Os depoimentos e os desenhos (Figura 7) obtidos nessa pesquisa evidenciam tal afirmativa.

"Tem que ter ótima qualidade, com um profissional apresentável e com equipamentos de primeira linha". (Depoimento de cliente/paciente que interrompeu o tratamento estético).

"Avalio bem quando a clínica tem equipamentos, um ambiente limpo e organizado. Nem precisa ter aparelhos tão caros, mas eles têm que ter bom estado de conservação". (Depoimento de cliente/paciente que concluiu o tratamento estético).

Figura 7 - Dimensão funcional da imagem: presença de equipamentos/aparelhos no local de trabalho.
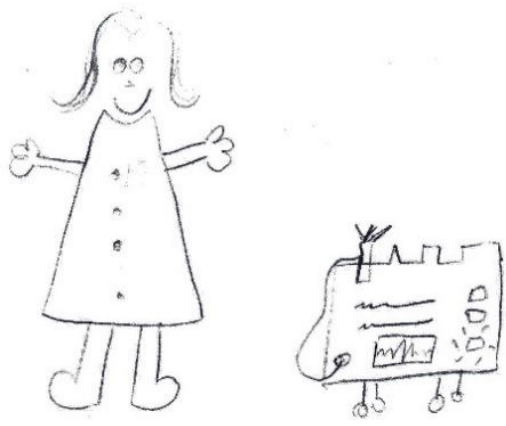

7A

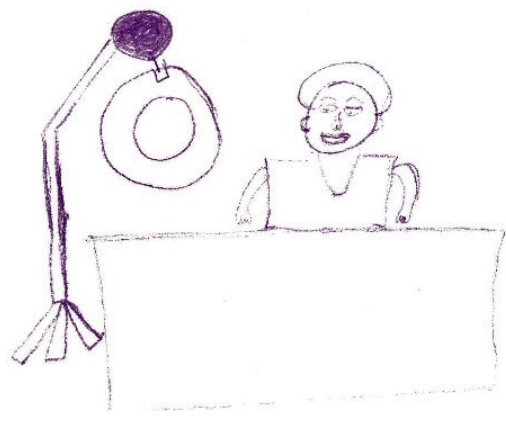

7B

Fonte: Dados da pesquisa.

Nota: Desenhos desenvolvidos por (7A) cliente/paciente que interrompeu o tratamento estético; (7B) estudante de curso técnico de Estética.

Outros posicionamentos fizeram menção à biossegurança. Os entrevistados ressaltam a importância de o ambiente ser limpo, seguro e com as regras da vigilância sanitária para um local de Estética.

"Prezo um ambiente limpo e confortável, levando também em conta a biossegurança". (Depoimento de Esteticista atuante).

"Ambiente sempre limpo e com materiais esterilizados e alguns descartáveis". (Depoimento de Esteticista não atuante).

"Descreveria como o profissional que veste branco, com jaleco, ambiente sempre limpo, com os materiais organizados, os produtos com validade em dia". (Depoimento de Esteticista não atuante).

No tocante à apresentação e ao modo de se vestir, a imagem do esteticista quanto ao seu perfil ficou evidenciada pela necessidade de ter uma boa aparência, uma pele bem cuidada e, no quesito vestuário, a vestimenta deve ser branca ou de cor clara e estar sempre limpa, deve-se usar jaleco. Outro fator bastante citado é o uso dos EPI e a necessidade de as unhas estarem curtas e os cabelos presos, podendo ser destacadas as seguintes respostas:

"Modo de vestir tem que ser com roupas brancas, claras, sempre usar máscara, touca, luvas sempre que necessário. O profissional sempre tem que estar bem apresentado". (Depoimento de Esteticista atuante). 
"O profissional sempre veste branco, cabelos limpos e presos, unhas limpas, roupas limpas, perfume suave". (Depoimento de Esteticista não atuante).

"Pelo fato de o esteticista trabalhar com imagem, ele tem que ser uma pessoa que esteja com a pele, principalmente a pele, em estado melhor. (...). Porque ele é um cartão de visita, ele tem que ter uma pele legal, tem que estar com o cabelo preso. Penso que o jaleco tem que ficar mais limpinho... Não pode ter unha grande, ter esse cuidado". (Depoimento de Esteticista não atuante).

A Figura 8 ilustra essas informações e estão em consonância com os depoimentos citados anteriormente. Em 8A e 8B, podem ser observados um profissional com jaleco, touca e máscara. Em 8C, verifica-se uma pessoa com jaleco e touca; e o desenho $8 \mathrm{D}$ representa o profissional com jaleco, sapato fechado e mãos bem-feitas.

Figura 8 - Dimensão funcional da imagem: estilos de vestimenta do Esteticista.
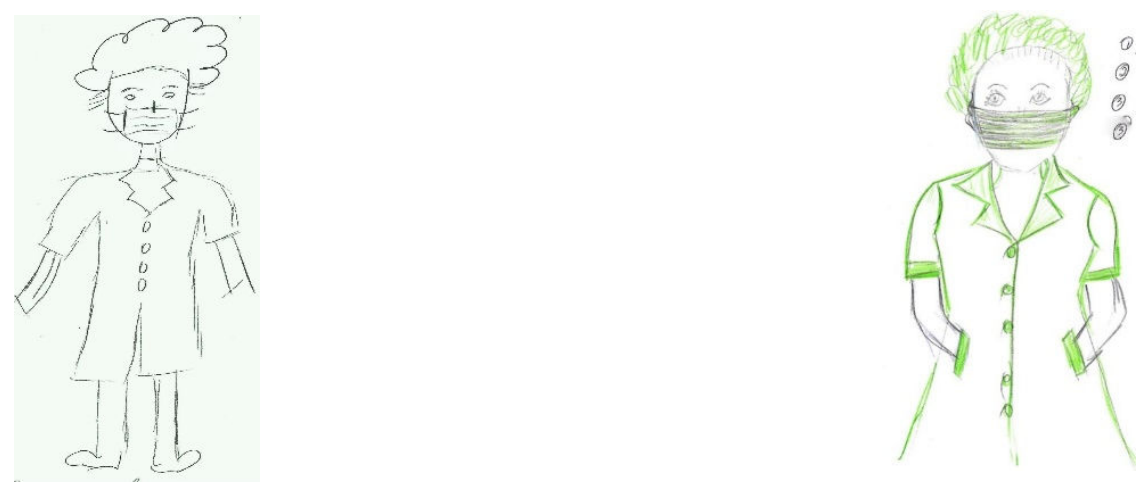

8A
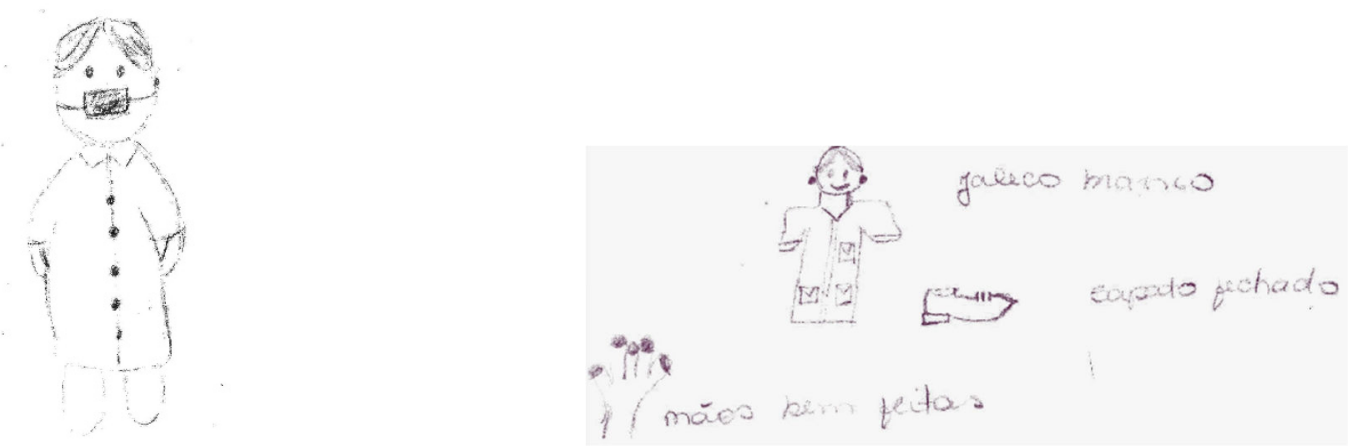

$8 \mathrm{C}$

Fonte: Dados da pesquisa.

Nota: Desenhos desenvolvidos por: (8A) médico dermatologista; (8B) cliente/paciente que interrompeu o tratamento estético; $(8 \mathrm{C})$ cliente/paciente que concluiu o tratamento estético e (8D) cliente/paciente potencial para tratamento estético.

De acordo com as declarações expostas, foi possível observar que o ambiente profissional tem que ser limpo, tranquilo, seguir as normas de biossegurança e ter equipamentos/aparelhos estéticos em bom estado de conservação. O profissional precisa ter uma boa aparência, usar roupas claras e fazer uso dos EPI. Porém, essas características podem ser vistas em diversos ambientes da área da saúde, e, por isso, não são características exclusivas dos esteticistas. Um ambiente de trabalho e uma apresentação mais definida da 
profissão e do profissional de Estética poderiam levar a uma formação de uma imagem mais específica e característica da profissão. Em consequência desse resultado, uma possível migração de profissionais da área da saúde para o contexto estético pode contribuir para uma imagem descaracterizada, ou mesmo, equivocada da profissão.

\section{Dimensão Emocional}

As emoções associadas à Estética referem-se à presença dos aspectos emocionais que envolvem o as relações entre o profissional que presta o serviço e o serviço prestado, propriamente dito. Emoções negativas e positivas podem ser despertadas na atividade do esteticista, de acordo com os vários stakeholders considerados nesta pesquisa.

As expressões "sinto prazer", "me traz felicidade", "me sinto feliz", encontradas nos depoimentos dos esteticistas atuantes e não atuantes, e nos depoimentos dos estudantes, confirmam a associação de emoções positivas à profissão.

"A Estética entrou em minha vida no início de uma depressão, eu era uma dona de casa e vivia para o lar, marido, filhos, me sentia inútil... quando resolvi voltar a estudar e depois de formada a trabalhar, eu percebi que além da oportunidade de gerar alegria, beleza e qualidade de vida para outras pessoas me tornei mais sensível e responsável por elas também. Hoje, quando saio de minha casa para exercer minha função, sinto prazer e acima de tudo responsabilidade com meu trabalho, por isso, estudo constantemente. Sou uma pessoa melhor hoje graças a minha profissão". (Depoimento de Esteticista atuante).

"Porque sempre gostei de me cuidar, e gosto de cuidar dos outros, nada melhor ajudar uma pessoa a levantar sua autoestima". (Depoimento de Esteticista não atuante).

Em seguida, o posicionamento da categoria clientes/pacientes (que interromperam o tratamento, que concluíram e os que se encontravam em tratamento) quanto às suas sensações e emoções. Como poderá ser observado nas declarações a seguir, essas emoções estão principalmente associadas ao resultado do serviço prestado.

"Sensação de autoestima elevada. Como a gente melhora a aparência automaticamente as sensações são as melhores possíveis. A gente passa a ter prazer em cuidar da gente, é uma melhora pessoal". (Depoimento de cliente/paciente que interrompeu tratamento estético).

"Ah, pra mim foi muito bom. Eu voltei a usar saia, não ficava mais encucada com a celulite. Meio que devolveu minha confiança e também aumentou minha autoestima". (Depoimento de cliente/paciente que interrompeu tratamento estético).

"Tenho uma sensação de bem-estar. É o meu momento de prazer. É como se fosse um presente que eu me dou toda semana". (Depoimento de cliente/paciente que interrompeu tratamento estético).

"Vendo a mudança do antes e depois, através das fotos, eu me senti bem com minha pele, fiquei até mais jovem (risos)". (Depoimento de cliente/paciente que finalizou tratamento estético). 
As palavras "autoestima", "relaxamento", "satisfação", "cuidado", "bem-estar" e "confiança", citadas por esses stakeholders, ratificam a presença de emoções positivas no decorrer da prestação de serviços de Estética. Nas figuras 9A e 9B, o coração entre duas pessoas simboliza um relacionamento com emoções positivas.

Figura 9 - Dimensão emocional da imagem: relação entre profissional e cliente/paciente.
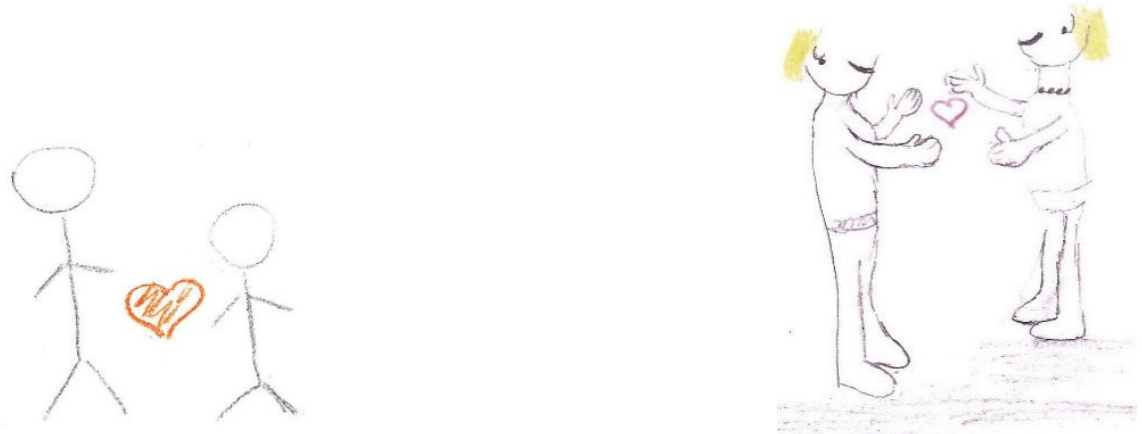

9A

Fonte: Dados da pesquisa.

Nota: Desenhos desenvolvidos por: (9A) esteticista atuante e (9B) esteticista não atuante.

Apenas um cliente/paciente foi neutro na resposta quanto às suas sensações e emoções, conforme se nota no seguinte depoimento:

"Nenhuma. Eu fui lá e fiz o que eu queria". (Depoimento de cliente/paciente que interrompeu tratamento estético).

Para a categoria de clientes/pacientes, a experiência de passar por um tratamento estético foi positiva. Mais uma vez, a maior parte dos clientes/pacientes relata as emoções positivas atreladas ao resultado do tratamento, como pode ser observado nos depoimentos e nas Figuras 10A e 10B.

"Experiência de confiança. Foi positiva a experiência porque eu consegui alcançar o que eu queria. Fiquei satisfeita". (Depoimento de cliente/paciente que interrompeu tratamento estético).

"Excelente, a que eu não gostei fui um dia só e não voltei. Foi positiva, porque contratei sabendo da sua competência". (Depoimento de cliente/paciente que interrompeu tratamento estético).

"Olha, até então está sendo bem positiva. Gosto de chegar e relaxar. Ela respeita meu silêncio e fala apenas quando é necessário. Não gosto de profissionais que ficam falando o tempo todo". (Depoimento de cliente/paciente em tratamento estético).

"Positiva. Estou bem satisfeita com os resultados e a duração dele. Consegui um resultado bem antes do que eu esperava". (Depoimento de cliente/paciente em tratamento estético). 
Figura 10 - Dimensão emocional da imagem: emoção positiva com relação ao tratamento estético.

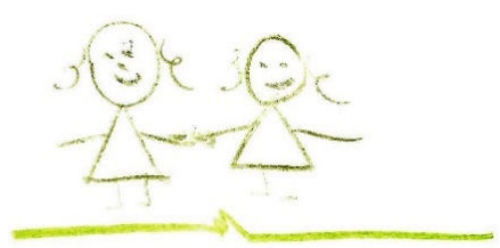

$10 \mathrm{~A}$

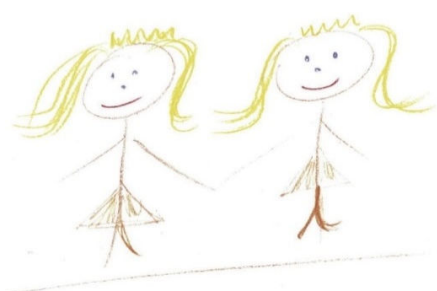

$10 B$

Fonte: Dados da pesquisa.

Nota: Desenhos desenvolvidos por: (10A) cliente/paciente em tratamento estético e (10B) cliente/paciente potencial para tratamento estético.

Este tópico identificou a presença dos aspectos emocionais no relacionamento entre o profissional que presta o serviço e o serviço prestado. A grande maioria relatou emoções positivas quanto aos serviços prestados.

\section{Dimensão Simbólica}

Com referência à dimensão simbólica da imagem, os stakeholders da Estética trazem consigo um grande número de símbolos representativos para a profissão. Esses símbolos se vinculam ao objetivo de melhorar a autoestima, promover bem-estar, melhorar a aparência, promover a beleza e gerar satisfação. Vale esclarecer que, para a dimensão simbólica, a avaliação dos serviços ocorre por meio da significação ou representação desses serviços para os indivíduos.

"Acho que eles veem o Esteticista como alguém que irá trazer bem-estar, cuidado e conforto". (Depoimento de Esteticista atuante).

"Bem-estar e saúde". (Depoimento de Esteticista não atuante).

"Significa elevar a autoestima do cliente". (Depoimento de Esteticista não atuante).

"Pra mim simboliza beleza, relaxamento, bem-estar. Os clientes sempre gostam do trabalho do esteticista". (Depoimento de estudante de Estética).

Por outro lado, para aqueles que são estudantes e esteticistas atuantes, a Estética aparece como a realização de um sonho e a possibilidade de poder trabalhar em algo com que se identificam.

"Estou realizando um sonho de ter um curso superior em uma profissão que eu amo". (Depoimento de estudante de Estética).

"Significa amar uma profissão". (Depoimento de estudante de Estética).

“...porque tenho me realizado profissionalmente, aplicando os conhecimentos adquiridos na minha graduação". (Depoimento de Esteticista atuante).

“(...) porque é uma coisa que eu gosto de fazer, sou apaixonada. Me identifiquei muito nessa área e o que eu faço, eu gosto muito". (Depoimento de Esteticista atuante). 
A Figura 11 representa o trabalho desenvolvido pelo esteticista e o resultado alcançado.

Figura 1 - Dimensão simbólica da imagem: simbolismo da profissão.

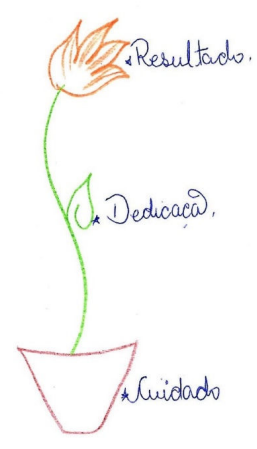

Fonte: Dados da pesquisa.

Nota: Desenho desenvolvido por professora de curso técnico em Estética.

No campo da dimensão simbólica, a avaliação dos serviços ocorre por meio da significação, como se pudesse ocorrer uma solução imediata, uma mágica para o objetivo que o paciente/cliente se propõe a alcançar. Há também depoimentos que incentivam um serviço multidisciplinar aliado a médicos e nutricionistas.

"Eu acho que ele representa a mágica. Eu não preciso fazer nada, alguém vai fazer por mim, eu sou o passivo, e alguém vai resolver meu problema por mim. Eu acho que se o esteticista começar a trabalhar mais em acões multidiciplinares, com os psicólogos, com os nutricionistas, com os médicos. Ele sendo parceiro, a visão da estética acaba mudando, deixa de ser beleza (...)". (Depoimento de professor de curso de Estética 2).

"Milagre. Perder gordura rápido sem fazer esforço, sabe, asim... alguns contratam também pra sentir algo, que alguém tá encostando nele, são pessoas muito solitárias, também. Mas, de uma maneira geral, eles querem milagre". (Depoimento de professor de curso de Estética).

"Hoje em dia, eles vão muito atrás da ilusão, eles acham que a Estética pode tudo, e não pode tudo. Eu acho que isso acontece muito por causa do marketing em cima. Os resultados que eles prometem, engana muito. (...) Ele vem com um objetivo específico sempre. $\mathrm{E}$, até o objetivo que ele chega nem sempre é o que realmente ele precisa". (Depoimento de coordenador de curso de Estética). 
As percepções de uma esteticista não atuante e a de um médico se baseiam na ideia que alguns clientes/pacientes buscam serviços de Estética com o objetivo de conquistar status.

"Pra alguns clientes representa a busca do bem-estar, da saúde, de uma melhora, da autoestima. Pra outros representam uma maneira de falar que tem dinheiro, que tá ostentando. E, pra outras, o esteticista é um meio de ajuda, uma melhora de uma postura, de saúde, de relaxamento, de estresse. Várias pessoas enxergam o esteticista de uma forma, pra alguns, ir ao esteticista quer dizer que você está esbanjando dinheiro, que você está ostentando. Pra outros, o esteticista é uma forma de buscar uma melhora de algo que não está bem nela". (Depoimento de Esteticista não atuante).

"Tenho percebido que para alguns é uma questão de status, há uma percepção de algumas pessoas mais pelo nome que pelo resultado final. Porém, ao mesmo tempo, consigo ver posturas que demonstram mais que isso, como uma apresentação totalmente voltada por resultados mais completos". (Depoimento de Médico).

Conforme os exemplos a seguir, pode-se notar que alguns stakeholders veem o esteticista como alguém responsável pela melhora da aparência física e, com os resultados obtidos, contribui para a melhora emocional dos clientes/pacientes.

"Tem que gostar muito do que faz. Pra mim, o esteticista é uma pessoa que acaba tratando as angústias de muitas mulheres. O que a gente procura nem sempre é só aquilo. $\mathrm{O}$ esteticista tem que ter um feeling, e pensar como melhorar aquele problema sem interferir na vida pessoal da pessoa. É um cuidado que ele tem que ter com o cliente". (Depoimento de cliente/paciente em tratamento estético).

"Eu vejo assim que as pessoas acreditam que melhora sim, que vai ficar melhor, que vai ficar bem. É um trabalho que às vezes você mexe até com o psicológico de alguém. Às vezes, a pessoa chega aqui brava, nervosa, aí ela tá mais bonita, ela se sente um pouco mais calma". (Depoimento de ofício ligado a Estética).

"Via como uma profissão de cuidados com corpo e para o bem-estar físico, com o objetivo de buscar o belo nas pessoas. Depois que fiz o curso, eu percebi que é algo mais profundo, que tem a ver com a saúde física e mental das pessoas". (Depoimento de Esteticista não atuante).

O semblante triste do cliente e os braços estendidos do esteticista representam a ajuda oferecida pelo profissional para melhorar o emocional do cliente, conforme mostra a Figura 12.

Figura 12 - Dimensão simbólica da imagem: simbolismo de ajuda.

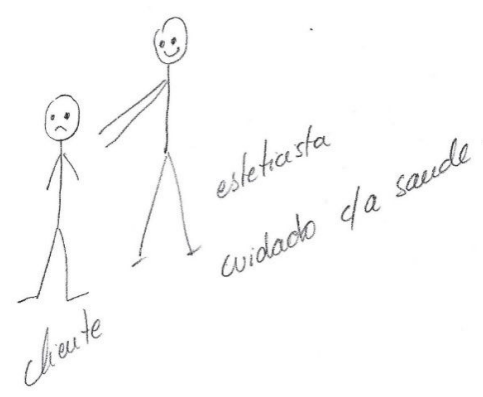

Fonte: Dados da pesquisa.

Nota: Desenho desenvolvido por professora de curso de graduação em Estética. 
Em resumo, pode-se considerar que, para os demais stakeholders, a dimensão simbólica da imagem da profissão de Estética é a representação de bem-estar, da contribuição para a melhora da autoestima e da aparência física, e do trabalho não só com o físico, mas também com o emocional. Assim, considera-se ainda que a dimensão simbólica da imagem da profissão de Estética é a representação de uma realização pessoal para o profissional da área.

\section{CONSIDERAÇÕES FINAIS}

Com base na literatura, os estudos de Dobni e Zinkhan (1990), De Toni (2005), Milan, Gasparini e De Toni (2013) e Milan et al. (2014) foram adotados para uma melhor compreensão da imagem da Estética, do Esteticista e desse campo de trabalho. Assim sendo, o objetivo proposto foi compreender qual a percepção que stakeholders da Estética possuem em relação à imagem da profissão e do profissional nas dimensões cognitiva, funcional, simbólica e emocional, e algumas conclusões serão apresentadas a seguir.

Quando à dimensão cognitiva - que se refere à construção mental, racional e lógica da imagem que um indivíduo tem sobre um produto ou serviço, a imagem do profissional de Estética foi percebida em toda a sua amplitude e foram ressaltados os seguintes aspectos:

- Necessidade de constante aprimoramento técnico e científico por parte do profissional Esteticista, devido à sua responsabilidade não apenas relacionada as ações que proporcionam a beleza aos clientes, mas também por ações ligadas à saúde ao cliente.

- Necessidade de ajuda por parte dos próprios clientes, para que possam obter os resultados propiciados pelos diversos tratamentos.

Esse resultado confirma as ideias de Carvalho (2006), para quem a formação do profissional de Estética deve prepará-lo com um amplo conhecimento técnico-científico no sentido de permitir sua inserção no campo da saúde. O mesmo pode-se dizer da profissão de bibliotecário, que por suas funções ainda serem desconhecidas, os profissionais devem ser treinados e atualizados constantemente, para que assim reforcem seu papel no ambiente escolar (JAIME, 2012). Um outro dado importante, encontrado na dimensão cognitiva, foi o fato dos stakeholders apresentarem uma visão limitada em relação aos campos de atuação da Estética.

Quanto à dimensão funcional, a imagem do profissional da área de Estética está atrelada às características do seu perfil profissional, ao contexto do seu trabalho e ao seu vestuário. Em relação ao perfil do profissional de Estética foram citados os pontos:

- boa aparência, pele bem cuidada, unhas curtas;

- uso de equipamentos de proteção individual;

- conhecimentos teóricos e práticos, constante aperfeiçoamento e domínio de tecnologias.

Quanto ao contexto, os pontos citados foram:

- limpeza do local de atendimento;

- tranquilidade no local de atendimento;

- biossegurança; 
- presença de equipamentos/aparelhos estéticos de última geração;

- importância da individualidade no atendimento.

Quanto ao vestuário, houve consenso em vestimenta branca ou de cor clara, e uso obrigatório de um jaleco. Contudo, como o esteticista tem a mesma especificação de um profissional da área da saúde, isso pode contribuir para uma nebulosidade da dimensão funcional.

No tocante à dimensão simbólica, ela pode ser definida como a maneira que um serviço ou produto são avaliados pelo que significam ou representam para o indivíduo. Neste estudo, os posicionamentos indicaram que os profissionais da Estética:

- melhoram a autoestima das pessoas;

- promovem bem-estar dos clientes;

- melhoram a aparência dos clientes;

- promovem a beleza;

- geram satisfação.

Para estudantes e esteticistas, a Estética aparece como a realização de um sonho. Para outros respondentes, clientes/pacientes buscam serviços de Estética com o objetivo de conquistar status, corroborando com Milan, Gasparini e De Toni (2013), ao confirmarem que o valor simbólico está relacionado aos sentimentos, valores e objetivos do consumidor, seja para sua própria imagem (autoestima) ou para a imagem perante as outras pessoas (status). Isso mostra que a Estética pode ser considerada como um mercado de luxo, reforçando as ideias anteriores de que só usufruem de seus serviços, indivíduos que apresentam um poder aquisitivo maior. Assim, a Estética pode ser vista por muitos como um serviço caro e de pouco acesso, o que limita a área de atuação dos esteticistas. Mais uma vez, esses dados reforçam a importância do reconhecimento da Estética na área da saúde, já que seus serviços favorecem a melhora da qualidade de vida, conforme os estudos de Bailey et al. (2011).

A dimensão emocional se refere aos sentimentos, às emoções e aos estados de ânimo que o indivíduo possui em relação a determinado produto ou serviço. Na dimensão emocional, as emoções positivas e negativas associadas à Estética registram as maneiras pelas quais ocorre o relacionamento entre clientes/pacientes e o profissional que presta esse serviço.

Neste estudo, foi observada a predominância de relatos de emoções positivas, dirigidas tanto ao processo da prestação de serviço (autoestima, relaxamento, satisfação, cuidado, bem-estar, confiança) quanto aos resultados atingidos por meio dessa prestação de serviços. As emoções estão principalmente associadas ao resultado propiciado pelo serviço contratado, ressaltando-se que essas emoções positivas também foram relatadas pelos profissionais e estudantes da área em relação à profissão (sinto prazer, me traz felicidade, me sinto feliz). Esse resultado pode ser confirmado pelo estudo de Vough et al. (2013), no qual foi possível perceber que os profissionais entrevistados acreditavam que a percepção ruim de seus papéis pelos clientes leva não só à desvalorização de sua profissão, como também a expectativas desalinhadas sobre o processo e resultados na relação cliente/profissional. Embora a maior parte dos stakeholders tenha relatado emoções positivas, não podem ser excluídas interferências das emoções negativas quanto aos 
resultados do serviço. Segundo Ferreira, Moura e Souki (2014), o mesmo foi encontrado em relação à profissão do farmacêutico, na qual as emoções mais citadas foram positivas, mas não deixaram de existir também as negativas, o que pode ser um determinante na escolha do serviço.

Portanto, pode-se afirmar que, mesmo sendo uma profissão que atua na imagem física das pessoas, a Estética não está sendo capaz de trabalhar sua própria imagem profissional no Brasil, da mesma forma que identificam alguns estudos revisados sobre outras profissões ao redor do mundo.

Acredita-se que a inexistência de um órgão regulador de leis e/ou regras da profissão tem contribuído para a formação de uma imagem profissional distorcida, bem como para o crescimento do número de profissionais ligados à saúde que acabam migrando para a área da Estética o que contribui para o sombreamento do profissional esteticista.

Finalizando, acredita-se que a compreensão da imagem profissional possa contribuir para a formulação e implementação das estratégias de marketing eficazes, importantes para direcionar as ações estratégicas para a profissão e o profissional da Estética.

\section{REFERÊNCIAS}

ALMEIDA, S. M. Marketing em profissões: um estudo sobre a imagem da fonoaudiologia. 2011. 253f. Dissertação (Mestrado em Administração) - Faculdade de Ciências Econômicas Administrativas e Contábeis, Universidade FUMEC, Belo Horizonte, 2011.

AMORIM, A. A. Marketing de serviços: um estudo exploratório sobre a imagem e a identidade da fisioterapia. 2009.136 f. Dissertação (Mestrado em Administração) -Faculdade de Ciências Econômicas Administrativas e Contábeis, Universidade FUMEC, Belo Horizonte, 2007.

BAILEY, E. E.; ASHFAQ, A. M.; ORENGO, I. F.; TESTA, M. A.; WHITE, V. R.; GELLER, A. C. Skin cancer knowledge, attitudes, and behaviors in the salon: a survey of working hair professionals in Houston, Texas. Archives of Dermatological Research, v. 147, n. 10, p. 1159-1165, 2011.

BARDIN, L. Análise de conteúdo. São Paulo: Edições 70, 2011.

BARICH, H.; KOTLER, P. A framework for marketing image management. Sloan Management Review, v. 32, n. 2, p. 97104, 1991.

BAUMEISTER, R. F. A self-presentational view of social phenomena. Psychological Bulletin, n.91, n. 1, p.3-26, 1982.

BRASIL. Lei 13.643, 03 de abril de 2018. Disponível em: http://www2.camara.leg.br/legin/fed/lei/2018/lei-13643-3-abril2018-786398-publicacaooriginal-155154-pl.html. Acesso em: 04 abr. 2018.

CARVALHO, C. R. F. Estudo do perfil profissional e da formação acadêmica do tecnólogo em estética: Estudo de caso. 2006. 196 p. Dissertação (Mestrado em Ensino em ciências e Biociências em Saúde) - Fundação Oswaldo Cruz, Rio de Janeiro, 2006. Disponível em: http://www.pucpr.br/eventos/educere/educere2006/anaisEventos/docs/Cl-117-TC.pdf. Acesso em: 25 set. 2014.

DE TONI, D. Administração da imagem de produtos: desenvolvendo um instrumento para a configuração da imagem de produto. 2005. 268 f. Tese (Doutorado em Administração) - Universidade Federal do Rio Grande do Sul, Porto Alegre, 2005.

DE TONI, D.; MILAN, G. S.; BARAZETTI, L. Imagens de serviços: um estudo exploratório sobre a configuração e organização das imagens dos serviços de fisioterapia de um plano de saúde. In: ENCONTRO ANUAL DA ANPAD, v. 28, 2004, Curitiba. Anais do XXVIII ENANPAD. Curitiba: ANPAD, 2004.

DE TONI, D.; MILAN, G. S.; SCHULER, M. Configuração de imagens de serviços: um estudo aplicado aos serviços de fisioterapia disponibilizados por um plano de saúde. In: ANAIS DO ENCONTRO ANUAL DA ANPAD, v. 29. Brasília: ENANPAD, 2005.

DE TONI, D.; SCHULER, M. Gestão da imagem: desenvolvendo um instrumento para a configuração da imagem de produto. Revista de Administração Contemporânea, v. 11, n. 4, p. 131-151, 2007.

DICHTER, E. What's in an image. The Journal of Consumer Marketing, v. 2, n. 1, p. 75-81, 1985.

DOBNI, D.; ZINKHAN, G. M. In search of brand image: a foundation analysis. Advances in Consumer Research, v. 17, n. 1 , p. 110-119, 1990. 
FERREIRA, C. L.; MOURA, L. R. C.; SOUKI, G. Q. A imagem de profissões da saúde sob a perspectiva do marketing. Revista de Administração IMED, v. 4, n. 3, p. 343-355, 2014.

FERREIRA, L. F. Imagem do farmacêutico: proposição e teste de um modelo de avaliação. Dissertação (Mestrado em Administração) - Centro Universitário Una, Belo Horizonte, 2014.

GASPARIN, F. M. A configuração da imagem de um shopping Center na percepção de consumidores locais. $2011.115 f$. Dissertação (Mestrado em Administração) - Universidade de Caxias do Sul, Caxias do Sul, 2011.

GIACALONE, R.; ROSENFELD, P. Applied impression management: How image-making affects managerial decisions. Newbury Park, CA: Sage Publications, 1991.

GONZALEZ, J. A.; CHAKRABORTY, S. Image and similarity: an identity orientation perspective to organizational identification. Leadership \& Organization Development JournaL, v. 33, n. 1, p. 51-65, 2012.

GRASSELI, M. Marketing na arquitetura: um hiato entre a imagem e a identidade profissional.2007. 145f. Dissertação (Mestrado em Administração) - Faculdade de Ciências Econômicas Administrativas e Contábeis, Universidade FUMEC, Belo Horizonte, 2007.

HOEVE, Y. T.; JANSEN, G.; ROODBOL, P. The nursing profession: public image, self-concept and professional identity; a discussion paper. Journal of Advanced Nursing, v. 70, n. 2, p. 295-309, 2014.

IBARRA, H. Provisional selves: experimenting with image and identity in professional adaptation. Administrative Science Quarterly, v.44, n. 4, p. 764-791, 1999.

JAIME, F. M. La imagen profesional del bibliotecario escolar: la percepción de los directivos y la autopercepción de los bibliotecarios de las escuelas primarias de la ciudad de Rafaela, Santa Fe. Información, Cultura Y Sociedad, n. 27, p.5590, 2012

JOLY, M. Introdução à análise da imagem. 6. ed. São Paulo: Papirus Editora, 2003. 152 p.

LEARY, M. R.; KOWALSKI, R. M. Impression management: a literature review and two-component model. Psychological Bulletin, v. 107, n. 1, p. 34-47, 1990.

LEDOUX, J. O cérebro emocional: os misteriosos alicerces da vida emocional. Rio de Janeiro: Objetiva, 2001.

LITTLE, L. M.; MAJOR, V. S.; HINOJOSA, A. S.; NELSON, D. L. Professional image maintenance: how women navigate pregnancy in the workplace. Academy of Management Journal, vol. 58, n. 1, p. 8-37, 2015.

LOVELOCK, C.; WRIGHT; L. Serviços: marketing e gestão. Tradução: Cid Knipel Moreira. São Paulo: Saraiva, 2005. 416 p.

LOPUKHOVA, O. G. Dynamics of psychology students' "image of a psychologist" conception during education. ProcediaSocial and Behavioral Sciences, v. 159, p. 120-124, 2014.

MACHADO, A. J. Imagem do programa de orientação e proteção ao consumidor: um estudo sobre as percepções de consumidores, advogados e representantes de procons e empresas do segmento financeiro. 2010. 107 f. Dissertação (Mestrado em Administração) - Faculdade de Ciências Econômicas, Universidade FUMEC, Belo Horizonte, 2010.

MACHADO-DA-SILVA, C. L.; FONSECA, V. S.; FERNANDES, B. H. R. Cognição e institucionalização na dinâmica da mudança em organizações. In: RODRIGUES, S. B.; CUNHA, M. P. (Orgs.). Estudos organizacionais: novas perspectivas na administração de empresas, uma coletânea luso-brasileira. São Paulo: Iglu, p. 123-150, 2000.

MENDES, R. L. Marketing na Psicologia: um estudo exploratório sobre a imagem profissional. 2008. 169 f. Dissertação (Mestrado em Administração) - Faculdade de Ciências Econômicas Administrativas e Contábeis, Universidade FUMEC, Belo Horizonte, 2008.

MENDES, R. L; SOUKI, G. Q.; GRASSELI, M. Professional image in marketing: an exploratory study about the functional dimension in psychology. In: ACADEMY OF MARKETING ANNUAL CONFERENCE. Aberdeen, 2008.

MILAN, G. S.; ALTHAUS, A. A.; DE TONI, D.; EBERLE, L.; LAZZARI, F. A imagem dos acessórios de esquadrias de pvc: um estudo comparativo entre os produtos de origem chinesa e europeia. Qualitas Revista Eletrônica, v. 15, n. 1, 2014. Disponível em: http://revista.uepb.edu.br/index.php/qualitas/article/view/2108/1087. Acesso em: 29 de fev. 2016.

MILAN, G. S.; DE TONI, D. A configuração das imagens dos gestores sobre o conceito de estratégia. Revista de Administração Mackenzie, v. 9, n. 6, p. 102-125, set./out. 2008.

MILAN, G. S.; DE TONI, D.; SCHULER, M. Configuração de imagens: um estudo com serviços de fisioterapia. Gestão.Org Revista Eletrônica de Gestão Organizacional, v. 6, n. 1, p. 19-36, 2010.

MILAN, G. S.; GASPARIN, F. M.; DE TONI, D. A configuração da imagem de um shopping center na percepção de consumidores locais. REAd - Revista Eletrônica da Administração, v. 19, n. 1, p. 83-114, 2013.

O'NEILL, R.; LAMBERT, D. R. The emotional side of price. Psychology \& Marketing, v. 18, n. 3, p. 17-237, 2001.

RODRÍGUEZ, C.; PAWLIKOWSKA, T.; SCHWEYER, F. X.; LÓPEZ-ROIG, S.; BÉLANGER, E.; BURNS, J.; HUGÉ, S.; PASTOR-MIRA, M. A.; TELLIER, P. P.; SPENCER, S.; FIQUET, L.; PEREIRÓ-BERENGUER, I. Family physicians' 
professional identity formation: a study protocol to explore impression management processes in institutional academic contexts. BMC Medical Education, v. 14, p. 184, 2014.

ROSENFELD, P., GIACALONE, R.; RIORDAN, C. Impression management: building and enhancing reputations at work. Cengage Learning EMEA, 2001. 264 p.

SCHLENKER, B. R. Self-presentation. In: LEARY, M.; TANGNEY, J. (Eds.). Handbook of self and identity. New York: The Guilford Press, 2003. 703 p.

SERVIÇO BRASILEIRO DE APOIO ÁS MICRO E PEQUENAS EMPRESAS (SEBRAE). Perspectivas de mercado até 2015: higiene pessoal, perfumaria e cosméticos. Disponível em: http://www.sebraemercados.com.br/perspectivas-demercado-ate-2015-higiene-pessoal-perfumaria-e-cosmeticos/. Acesso em: 15 dez. 2015.

STERN, B.; ZINKHAN, G.; JAJU, A. Marketing images: construct definition, measurement issue, and theory development. Marketing Theory, v. 1, n. 2, p. 201-224, 2001.

TICE, D.; WALLACE, H. The reflected self: creating yourself as (you think) others see you. In: LEARY, M.; TANGNEY, J. (Eds.). Handbook of self and identity. New York: The Guilford Press, p.91-105, 2003.

VICTER, P. P. Marketing no turismo: Um estudo descritivo sobre a imagem do intercâmbio de cursos de idiomas. 2009. 138 f. Dissertação (Mestrado em Administração) - Faculdade de Ciências Econômicas Administrativas e Contábeis, Universidade FUMEC, Belo Horizonte, 2009.

VOUGH, H. C.; CARDADOR, M. T.; BEDNAR, J. S.; DANE, E.; PRATT, M. G. What clients don't get about my profession: a model of perceived role-based image discrepancies. Academy of Management Journal, v. 56, n. 4, p. 1050-1080, 2013.

ZIELKE, S. Integrating emotions in the analysis of retail price images. Psychology \& Marketing, v. 28, n. 4, p. 330-359, 2011. 